\title{
Observation-based assessment of stratospheric fractional release, lifetimes, and ozone depletion potentials of ten important source gases
}

\author{
J. C. Laube ${ }^{1}$, A. Keil ${ }^{2}$, H. Bönisch ${ }^{2}$, A. Engel $^{2}$, T. Röckmann ${ }^{3}$, C. M. Volk ${ }^{4}$, and W. T. Sturges ${ }^{1}$ \\ ${ }^{1}$ School of Environmental Sciences, University of East Anglia, Norwich, UK \\ ${ }^{2}$ Institute for Atmospheric and Environmental Sciences, University of Frankfurt, Frankfurt (Main), Germany \\ ${ }^{3}$ Institute for Marine and Atmospheric Research, Utrecht University, Utrecht, the Netherlands \\ ${ }^{4}$ Department of Physics, University of Wuppertal, Wuppertal, Germany \\ Correspondence to: J. C. Laube (j.laube@uea.ac.uk)
}

Received: 9 October 2012 - Published in Atmos. Chem. Phys. Discuss.: 30 October 2012

Revised: 14 February 2013 - Accepted: 15 February 2013 - Published: 8 March 2013

\begin{abstract}
Estimates of the recovery time of stratospheric ozone heavily rely on the exact knowledge of the processes that lead to the decomposition of the relevant halogenated source gases. Crucial parameters in this context are fractional release factors (FRFs) as well as stratospheric lifetimes and ozone depletion potentials (ODPs). We here present data from the analysis of air samples collected between 2009 and 2011 on board research aircraft flying in the mid- and highlatitude stratosphere and infer the above-mentioned parameters for ten major source gases: $\mathrm{CFCl}_{3}(\mathrm{CFC}-11), \mathrm{CF}_{2} \mathrm{Cl}_{2}$ (CFC-12), $\mathrm{CF}_{2} \mathrm{ClCFCl}_{2}$ (CFC-113), $\mathrm{CCl}_{4}$ (carbon tetrachloride), $\mathrm{CH}_{3} \mathrm{CCl}_{3}$ (methyl chloroform), $\mathrm{CHF}_{2} \mathrm{Cl}$ (HCFC22), $\mathrm{CH}_{3} \mathrm{CFCl}_{2}$ (HCFC-141b), $\mathrm{CH}_{3} \mathrm{CF}_{2} \mathrm{Cl}$ (HCFC-142b), $\mathrm{CF}_{2} \mathrm{ClBr}(\mathrm{H}-1211)$, and $\mathrm{CF}_{3} \mathrm{Br}(\mathrm{H}-1301)$. The inferred correlations of their FRFs with mean ages of air reveal less decomposition as compared to previous studies for most compounds. When using the calculated set of FRFs to infer equivalent stratospheric chlorine, we find a reduction of more than $20 \%$ as compared to the values inferred in the most recent Scientific Assessment of Ozone Depletion by the World Meteorological Organisation (WMO, 2011). We also note that FRFs and their correlations with mean age are not generally time-independent as often assumed. The stratospheric lifetimes were calculated relative to that of CFC-11. Within our uncertainties the ratios between stratospheric lifetimes inferred here agree with the values in recent WMO reports except for CFC-11, CFC-12 and $\mathrm{CH}_{3} \mathrm{CCl}_{3}$. Finally, we calculate lower ODPs than recommended by WMO for six out of
\end{abstract}

ten compounds, with changes most pronounced for the three HCFCs. Collectively these newly calculated values may have important implications for the severity and recovery time of stratospheric ozone loss.

\section{Introduction}

Large-scale ozone depletion in the stratosphere is still occurring on an annual basis in the higher latitudes of both hemispheres, with full recovery being projected around the middle of this century (WMO, 2011). A number of mainly man-made chorine- and bromine-containing trace gases have long been identified to be largely responsible for this phenomenon (WMO, 1990). The effects of these ozone depleting substances (ODSs) are often quantified via their respective fractional release factors (FRFs). These were first defined by Solomon and Albritton (1992) as "the fraction of the halocarbon species $x$ injected into the stratosphere that has been dissociated". Knowledge of these measures is of major importance for the quantification of the ability of ODSs to destroy ozone with larger FRFs, resulting in more ozone being destroyed. Earlier studies have derived FRFs relative to that of CFC-11 (Solomon et al., 1992; Daniel et al., 1995; Schauffler et al., 1999, 2003), whereas more recent studies focused on FRF-mean-age correlations (Newman et al., 2006, 2007; Laube et al., 2010a). 
The stratospheric lifetimes of these ODSs are equally important in this context as the recovery time of the ozone layer will depend on these quantities. This is especially true in the case of the chlorofluorocarbons, where the stratospheric lifetimes are equivalent to the overall atmospheric lifetimes. One of the most important observation-based studies of stratospheric lifetimes is that of Volk et al. (1997), who used and further developed the theoretical framework of Plumb and Ko (1992) and Plumb (1996) to infer steady-state lifetimes of six important ozone-depleting halocarbons: $\mathrm{CFCl}_{3}$ (CFC-11), $\mathrm{CF}_{2} \mathrm{Cl}_{2}$ (CFC-12), $\mathrm{CF}_{2} \mathrm{ClCFCl}_{2}$ (CFC-113), $\mathrm{CCl}_{4}$ (carbon tetrachloride), $\mathrm{CH}_{3} \mathrm{CCl}_{3}$ (methyl chloroform), and $\mathrm{CF}_{2} \mathrm{ClBr}(\mathrm{H}-1211)$. For this purpose they utilised the compact correlations that long-lived trace gases form with each other and also with the mean ages of air (i.e. the mean stratospheric transit times). We here use a similar method and measurements on air samples collected in the mid- and high-latitude stratosphere to evaluate the stratospheric lifetimes of ten important ODSs: CFC-11, CFC-12, CFC-113, $\mathrm{CCl}_{4}, \mathrm{CH}_{3} \mathrm{CCl}_{3}, \mathrm{CHF}_{2} \mathrm{Cl}$ (HCFC-22), $\mathrm{CH}_{3} \mathrm{CFCl}_{2}$ (HCFC141b), $\mathrm{CH}_{3} \mathrm{CF}_{2} \mathrm{Cl}$ (HCFC-142b), $\mathrm{H}-1211$, and $\mathrm{CF}_{3} \mathrm{Br}$ (H1301). Moreover, the calculation of the FRFs and their relation to mean ages of air enables us to derive observationbased semi-empirical ozone depletion potentials (ODPs) for these compounds.

\section{Sample collection, measurements and data analysis}

The air samples were collected using whole-air samplers operated on board the M55 Geophysica high altitude aircraft (see Kaiser et al., 2006, and Laube et al., 2010a, for details on the sampling systems and Cairo et al., 2010, for a description of a typical Geophysica campaign and payload). Two Geophysica flights departed from Oberpfaffenhofen, Germany, on 30 October and 4 November 2009 (covered altitude, latitude and longitude ranges: $10-20 \mathrm{~km}, 48-54^{\circ} \mathrm{N}, 7-12^{\circ} \mathrm{E}$ ) and nine from Kiruna, Sweden, between 20 January and 2 February 2010, and on 11 and 16 December 2011 (9-19km, $62-77^{\circ} \mathrm{N}, 1^{\circ} \mathrm{W}-29^{\circ} \mathrm{E}$, RECONCILE and ESSENCE campaigns). The samples were then analysed via gas chromatography with mass spectrometric detection (GC-MS): 138 samples at the University of East Anglia (UEA, see Laube et al., 2010b, for analysis details) and 72 at the University of Frankfurt (UFra). All samples analysed in Frankfurt were measured using a system similar to the one at UEA except that the detector is a quadrupole mass spectrometer (Agilent 5975 MSD). In addition to the compounds mentioned above, we used measurements of $\mathrm{SF}_{6}$ to infer stratospheric mean ages of air.

All data underwent a thorough quality check as is explained in the following. Some of the measurements carried out at UFra showed significantly worse analytical precision than the UEA measurements. These data were excluded based on the following procedure: first we calculated the av- erage $2 \sigma$ precision (in $\%$ ) of all samples analysed at UEA. In order to represent the range of precisions observed at UEA, we then derived the $2 \sigma$ standard deviation of this average precision. UFra measurements with relative precisions larger than this range were excluded (CFC-11: 6 samples, CFC113: 13, HCFC-141b: 13, H-1301: all, H1211: $35, \mathrm{CH}_{3} \mathrm{CCl}_{3}$ : 26) In addition, most samples from the 2010 and $2011 \mathrm{cam}$ paigns were contaminated with several parts per trillion (ppt) of HCFC-142b and were consequently excluded. For $\mathrm{CCl}_{4}$ we excluded the 2010 data as these samples were analysed several months after collection and $\mathrm{CCl}_{4}$ is not stable in the stainless steel canisters over such extended periods (see also Laube et al., 2008). Finally, $\mathrm{SF}_{6}$ data from all UFra samples and also from the 2011 Geophysica campaign (the latter was analysed exclusively at UEA) could not be used for the calculation of mean ages of air due to limited instrument precisions at the time.

Table 1 shows the calibration scales used and the average measurement precisions of the remaining data set. Also displayed is a comparison of mixing ratios observed close to the tropopause with northern hemispheric $(\mathrm{NH})$ monthly mean mixing ratios as reported by the ground-based NOAA-ESRL network. The latter were obtained from http://www.esrl.noaa. gov/gmd/ (see Montzka et al., 1999, and Hall et al., 2011, for details; GC-MS data from flasks were used except for $\mathrm{SF}_{6}$, CFC-11 and CFC-12, where combined data were available, and $\mathrm{CCl}_{4}$, where in situ data were preferred for the above mentioned reasons), with the exception of $\mathrm{H}-1301$ where no long-term global trend was available at the time. Thus the $\mathrm{H}-1301$ time series was obtained from archived samples collected at Cape Grim, Tasmania $\left(41^{\circ} \mathrm{S}, 145^{\circ} \mathrm{E}\right.$, Newland et al., 2012). This time series was shifted by one year to account for interhemispheric transport times (Levin and Hesshaimer, 1996) and showed very good agreement with the $\mathrm{H}$ 1301 mixing ratios observed close to the tropopause in this study.

We also compared long-term time trends as observed by both laboratories (NOAA and UEA) at the ground-based station at Cape Grim. Agreement within measurement uncertainties was observed for eight compounds. However, we found small but consistent offsets for three compounds: CFC-113 (+2\%, UEA-NOAA), HCFC-142b $(-2 \%)$ and $\mathrm{CH}_{3} \mathrm{CCl}_{3}$ (+4\%) (see Supplement). After correcting for these offsets, we further evaluated the comparability of the data sets by comparing the NOAA NH mixing ratios with our upper tropospheric values. We found them to agree within $3 \%$ for all substances except HCFC-22 and HCFC-142b in November 2009, and $\mathrm{CH}_{3} \mathrm{CCl}_{3}$ in November 2009 and January 2010. For the two HCFCs we found differences to NOAA of $3.7 \%$ and $5.1 \%$, respectively. For HCFC-142b we only have reliable data for November 2009 (see above), but in the case of HCFC-22 the observed difference is much smaller in January 2010, suggesting that atmospheric variability may have been the underlying cause. $\mathrm{CH}_{3} \mathrm{CCl}_{3}$ shows differences of -5.4 and $-4.2 \%$. It is however the shortest 
Table 1. Overview of reported compounds, calibration scales, average measurement precisions (including the $1 \sigma$ standard deviation of that average), and the percentage difference between mixing ratios observed close to the tropopause and northern hemispheric monthly mean mixing ratios as reported by the ground-based NOAA-ESRL network (except for H-1301; see text).

\begin{tabular}{llrrr}
\hline Compound & Calibration scale & $\begin{array}{r}\text { Average } \\
\text { measurement } \\
\text { precision [\%] }\end{array}$ & \multicolumn{2}{c}{$\begin{array}{c}\text { Differences with } \\
\text { NOAA-ESRL NH } \\
\text { monthly mean (\%) in }\end{array}$} \\
\cline { 4 - 5 } & & & -0.9 & -0.8 \\
& & $0.9 \pm 0.4$ & -0.6 & -0.6 \\
\hline $\mathrm{CFC}-11$ NOAA-1993 & NOAA-2002 & $1.1 \pm 0.8$ & 0.3 & -0.9 \\
$\mathrm{CFC}-113$ & NOAA-2006 & $1.0 \pm 0.7$ & 0.1 & 3.0 \\
$\mathrm{CFC}-12$ & NOAA-1994 & $1.9 \pm 1.1$ & -5.1 & - \\
$\mathrm{HCFC}-141 \mathrm{~b}$ & NOAA-1994 & $0.8 \pm 0.2$ & -3.7 & -0.5 \\
$\mathrm{HCFC}-142 \mathrm{~b}$ & NOAA-2006 & $1.0 \pm 0.5$ & 0.2 & 0.3 \\
$\mathrm{HCFC}-22$ & NOAA-2006-MS & $0.7 \pm 0.2$ & -1.6 & -2.1 \\
$\mathrm{H}-1301$ & NOAA-2006 & $1.4 \pm 0.9$ & -2.2 & - \\
$\mathrm{H}-1211$ & NOAA-2002 & $1.2 \pm 0.9$ & -5.4 & -4.2 \\
$\mathrm{CCl}_{4}$ & NOAA-2003 & $2.2 \pm 1.1$ & -2.2 & -1.5 \\
$\mathrm{CH}_{3} \mathrm{CCl}{ }_{3}$ & NOAA-2006 & $1.0 \pm 0.5$ & & \\
$\mathrm{SF}_{6}$ & & & & \\
\hline
\end{tabular}

lived of the compounds reported here and has dominant tropospheric sinks which could explain these differences between ground-based stations and the upper troposphere. Nevertheless, we consider the maximum difference as an additional uncertainty for the calculation of the stratospheric lifetimes of $\mathrm{CH}_{3} \mathrm{CCl}_{3}$ and HCFC-142b (Sect. 4.2). The 2011 data set could not be compared as the lowest altitude samples from these flights were collected deeper in the stratosphere and already showed significant decomposition.

Finally, we compared our $\mathrm{SF}_{6}$ and $\mathrm{CFC}-11$ mixing ratios during the seven 2010 Geophysica flights with in situ GCECD (Electron Capture Detector) measurements obtained by the High Altitude Gas Analyzer (HAGAR; see Werner et al., 2010 , for details) with average $1 \sigma$ precisions of $1.3 \%$ for $\mathrm{SF}_{6}$ and $1.9 \%$ for CFC-11. Both data sets from the Geophysica flights are reported on the same NOAA calibration scales and showed very good agreement within their $1 \sigma$ measurement uncertainties.

\section{Methodology}

\subsection{Fractional release and mean age of air}

Fractional release factors were calculated using the method described in Laube et al. (2010a), which is comparable to the one used in Schauffler et al. (2003) and Newman et al. (2006). To correct for the underlying tropospheric trend, we firstly infer the mean ages of air which can be described as average stratospheric transit times. Similar to a variety of other studies (e.g. Harnisch et al., 1996; Volk et al., 1997; Engel et al., 2009; Bönisch et al., 2009), we use measurements of $\mathrm{SF}_{6}$ for this purpose. For those flights with insufficient $\mathrm{SF}_{6}$ precision (exclusively high latitudes, see above), we used the 2010 high-latitude correlation between $\mathrm{SF}_{6}$ and CFC-12 mixing ratios $(\chi)$ to infer mean ages $(\Gamma)$ via Eq. (1).

$$
\begin{aligned}
\Gamma= & 9.78-0.0287 \cdot \chi_{\mathrm{CFC}-12}+6.884 \cdot 10^{-5} \cdot\left(\chi_{\mathrm{CFC}-12}\right)^{2} \\
& -9.19923 \cdot 10^{-8} \cdot\left(\chi_{\mathrm{CFC}-12}\right)^{3}
\end{aligned}
$$

This methodology is similar to the one in Laube et al. (2010a). The validity range of this polynomial is limited to the ranges observed, i.e. mean ages from 0 to 5.4 years and CFC-12 mixing ratios from 540 to 235 ppt. For 23 samples we inferred mean ages above 5.4 years, and consequentially these were excluded from further analysis. Moreover, mean ages derived via Eq. (1) can not be used to infer FRFs of CFC-12.

We then calculated the average mixing ratios that were present in the individual air parcel when it entered the stratosphere using the mean ages $\Gamma$ and a parameterisation of its relation to the squared width of the age spectrum $\Delta^{2}\left(\Delta^{2} / \Gamma=\right.$ $\Lambda=0.7$ as in Engel et al., 2002). Laube et al. (2010a) tested the sensitivity of this parameterisation with different ratios and found the corresponding changes to have little influence on fractional release. By relating these mixing ratios to the amount actually observed in the samples via Eq. (2) (adapted from Solomon and Albritton, 1992), we infer fractional release factors.

$\operatorname{FRF}_{i}(x, y, z, t)=\frac{\bar{\chi}_{i, \text { entry }}-\chi_{i}(x, y, z, t)}{\bar{\chi}_{i, \text { entry }}}$

$\chi_{i}(x, y, z, t)$ is the mixing ratio of a long-lived trace gas $i$ at stratospheric location $(x, y, z)$ and time $(t)$, and $\chi_{i \text {, entry }}^{-}$is the mixing ratio of $i$ when the air parcel entered the stratosphere. 


\section{Stratospheric lifetimes}

Volk et al. (1997) used the slope of correlations at the extratropical tropopause to derive stratospheric steady-state lifetimes via two different methods. We here use the relative method which is based on the knowledge of the lifetime of one tracer. According to Volk et al. (1997) and using CFC-11 as the reference tracer, the stratospheric lifetime $\tau$ of a tracer $i$ can then be obtained from Eq. (3).

$\tau_{i}=\frac{\tau_{\mathrm{CFC}-11} \cdot \frac{\bar{\sigma}_{i}}{\bar{\sigma}_{\mathrm{CFC}-11}}}{\left.\frac{d \sigma_{i}}{d \sigma_{\mathrm{CFC}-11}}\right|_{\mathrm{TP}}}$

$\bar{\sigma}$ is the average atmospheric mixing ratio in steady state, and $\left.\frac{d \sigma_{i}}{d \sigma_{\mathrm{CFC}-11}}\right|_{\mathrm{TP}}$ is the slope of the mixing ratio correlation at the extratropical tropopause in steady state.

The ratio of the stratospheric lifetimes is thus dependent on the atmospheric average mixing ratios and the slope at the extratropical tropopause of the correlation of the two tracers, and these quantities need to be evaluated in steady state. The steady-state atmospheric average mixing ratios may be derived with little error from observed (non-steady) mixing ratios $\left(\chi_{i}\right)$ as they are dominated by the troposphere, which is well-mixed (and thus close to steady state) for the longlived species considered here. However, observed slopes at the tropopause are heavily influenced by transience due to tropospheric growth or decline. We here use the method of Volk et al. (1997) (cf. Eq. 25 in that study) that relates the observed transient gradient of a tracer with respect to mean age at the tropopause $(d \chi / d \Gamma)$ to the respective gradient $d \sigma / d \Gamma$, corresponding to a steady state situation with the same tropopause mixing ratio as observed:

$\frac{d \sigma_{i}}{d \Gamma}=\frac{\frac{d \chi_{i}}{d \Gamma}+\gamma_{0, i} \cdot \sigma_{0, i}}{1-2 \cdot \gamma_{0, i} \cdot \Lambda}$

$\sigma$ is the steady-state mixing ratio (index $0=$ at the tropopause), $\gamma_{0}$ is the effective linear tropospheric growth rate in year ${ }^{-1}$ (cf. Volk et al. (1997), Eq. A13), and $\Lambda$ is the ratio of the squared width of the age spectrum $\Delta^{2}$ to mean age $\Gamma$.

In order to minimise uncertainties resulting from the gradients of tracers against mean age, we substitute $d \chi_{i} / d \Gamma$ with $\left(d \chi_{i} / d \chi_{\mathrm{CFC}-11}\right)\left(d \chi_{\mathrm{CFC}-11} / d \Gamma\right)$ in Eq. (4) instead of deriving gradients with respect to age (and subsequently correction factors) for each species as done in Volk et al. (1997). This leaves only the slope of CFC-11 against mean age to be determined in addition to the slopes relative to CFC- 11 . CFC-11 is one of the shorter-lived tracers considered here, thus giving a comparably large (and thus well-constrained) slope against mean age. Moreover, CFC-11 has one of the best precisions and the lowest number of excluded samples resulting in the most reliable data set.

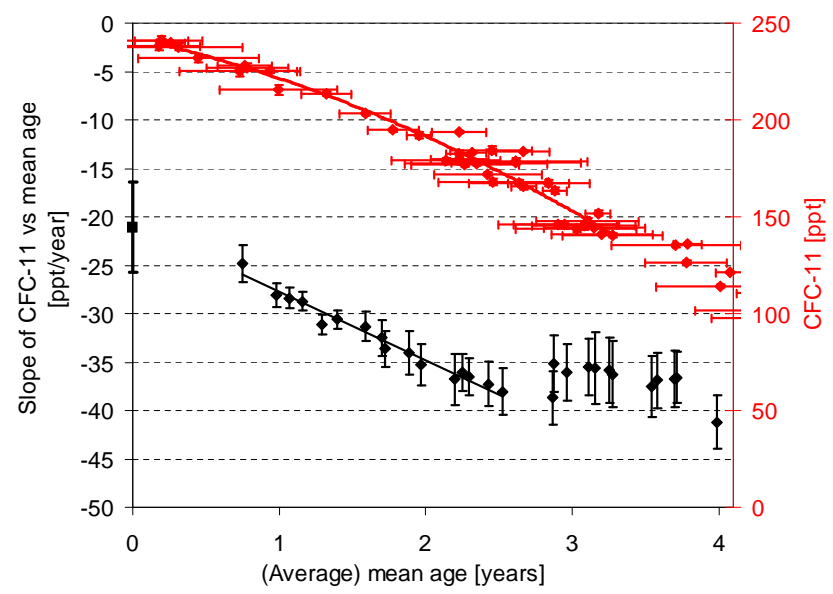

Fig. 1. Correlation of CFC-11 mixing ratios and mean age of air (red diamonds) and the corresponding slope evolution against the average mean age of air (black diamonds). Fitting a linear regression (black line) through the slope data between 0.7 and 2.5 years of average mean age yields a slope of $(-20.6 \pm 4.6) \mathrm{ppt} \mathrm{yr}^{-1}$ at a mean age of 0 (black square). The uncertainty of this y-intercept was estimated similar to Volk et al. (1997) using a "bootstrap" method (500 samples) and a scaling factor of the resulting uncertainty to account for the interdependency of the individual points.

The steady state slope relative to CFC-11 at the tropopause required in Eq. (3) is then readily obtained by using Eq. (4) for a tracer and for CFC-11:

$$
\begin{aligned}
& \frac{d \sigma_{i}}{d \sigma_{\mathrm{CFC}-11}}=\frac{d \sigma_{i} / d \Gamma}{d \sigma_{\mathrm{CFC}-11} / d \Gamma}= \\
& \frac{\frac{d \chi_{i}}{d \chi_{\mathrm{CFC}-11}} \frac{d \chi_{\mathrm{CFC}-11}}{d \Gamma}+\gamma_{0, i} \cdot \sigma_{0, i}}{\frac{d \chi_{\mathrm{CFC}-11}}{d \Gamma}+\gamma_{0, \mathrm{CFC}-11} \cdot \sigma_{0, \mathrm{CFC}-11}} \\
& \cdot \frac{1-2 \cdot \gamma_{0, \mathrm{CFC}-11} \cdot \Lambda}{1-2 \cdot \gamma_{0, i} \cdot \Lambda} .
\end{aligned}
$$

The less precise slope $d \chi_{\mathrm{CFC}-11} / d \Gamma$ now appears in both the nominator and denominator resulting in uncertainties partially cancelling out. Overall in Eq. (5) the principal information always comes from the well constrained $d \chi_{i} / d \chi_{\mathrm{CFC}-11}$.

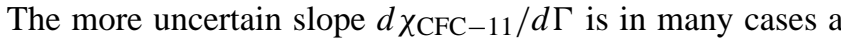
small correction term that only gains significant influence when tropospheric growth is very large. We calculate the effective linear growth rates $\gamma_{0}$ as in Volk et al. (1997) by approximating the tropospheric trend of the last 5 years as obtained from NOAA-ESRL (see Sect. 2) with a quadratic polynomial. $\Lambda$ is again a parameterisation of the width of the age spectrum, and we here use three different values $(0.7$, 1.25 and 1.75) to assess the resulting lifetime uncertainties.

We derive a slope against mean age of $(-20.6 \pm$ 4.6) $\mathrm{ppt} \mathrm{yr}^{-1}$ for $\mathrm{CFC}-11$ at a mean age of 0 which is equivalent to the chemical tropopause at CFC-11 $=241.0 \mathrm{ppt}$. Note that tropospheric mixing ratios of $\mathrm{CFC}-11$ have declined 
from the $270 \mathrm{ppt}$ used in the study of Volk et al. (1997), which we also take into account in Eqs. (3) to (5). In other respects our method is similar to that of Volk et al. (1997). Slopes along the CFC-11-age relation are measured by fitting linear regression lines over moving 2-year-mean age intervals using a bivariate error-weighted fit (Cantrell, 2008) to account for uncertainties in both axes. We then plot these slopes against the average mean age (see Fig. 1) and fit a regression line from 0.7 to 2.5 years that is extrapolated to derive the slope at the tropopause. We exclude data that could be influenced by the polar vortex (i.e. samples from the 2010 high-latitude campaign with CFC-11 mixing ratios $<140 \mathrm{ppt}$, which is equivalent to vortex data at a potential temperature of $\sim 380 \mathrm{~K})$ and choose a smaller age range as compared to Volk et al. (1997) (0.8 to 3.5 years), as we observe higher variability of the slopes at larger mean ages. The uncertainty of the tropopause slope value is estimated using the bootstrap technique in the same way as described in Volk et al. (1997).

Using $-20.6 \mathrm{ppt} \mathrm{yr}^{-1}$ as the slope of CFC-11 against mean age at the tropopause and the above mentioned substitutions yields Eq. (6) for the derivation of lifetimes relative to that of CFC-11.

$$
\begin{aligned}
\tau_{i}= & \tau_{\mathrm{CFC}-11} \cdot \frac{\bar{\sigma}_{i}}{\bar{\sigma}_{\mathrm{CFC}-11}} \cdot \frac{-20.6+\gamma_{0, \mathrm{CFC}-11} \cdot \sigma_{0, \mathrm{CFC}-11}}{-20.6 \cdot \frac{d \chi_{i}}{d \chi_{\mathrm{CFC}-11}}+\gamma_{0, i}} \\
& \sigma_{0, i} \cdot \frac{1-2 \cdot \gamma_{0, i} \cdot \Lambda}{1-2 \cdot \gamma_{0, \mathrm{CFC}-11} \cdot \Lambda}
\end{aligned}
$$

We calculate average atmospheric mixing ratios for January 2010 again using NOAA-ESRL data (i.e. global means) for the troposphere. For the stratosphere we fit average profiles of mixing ratio versus pressure to a data set including all Geophysica samples and in addition 44 samples collected on board stratospheric balloons launched by the French Space Agency CNES (Centre National d'Etudes Spatiales). Two of these balloon flights were launched from Kiruna in March 2009 and April 2011, while two others collected samples in the tropical stratosphere above Teresina, Brazil $\left(5^{\circ} \mathrm{S}\right.$, $42^{\circ} \mathrm{W}$ ), in June 2005 (see Laube et al., 2010a, for the latter; overall balloon altitude range: $10-34 \mathrm{~km}$ ). To account for differences in tropopause altitudes, we subdivide the stratosphere into area-weighted high- $\left(70-90^{\circ}\right)$, mid- $\left(25-70^{\circ}\right)$ and tropical- $\left(25^{\circ} \mathrm{N}-25^{\circ} \mathrm{S}\right)$ latitude bins. We estimate the uncertainties of these profiles by varying the boundaries between the three regions by $\pm 5^{\circ}$. To simulate the variability of the pressure tropopause, the profiles were shifted by $\pm 20 \%$ above $400 \mathrm{hPa}$. The respective uncertainties in average atmospheric mixing ratios were less than $2.1 \%$ in all cases. All average mixing ratios and effective linear growth rates can be found in the Supplement.

The most crucial observational quantity in Eq. (6), accounting for the major part of the uncertainty of the lifetime result, is the slope of mixing ratio versus CFC-11 at
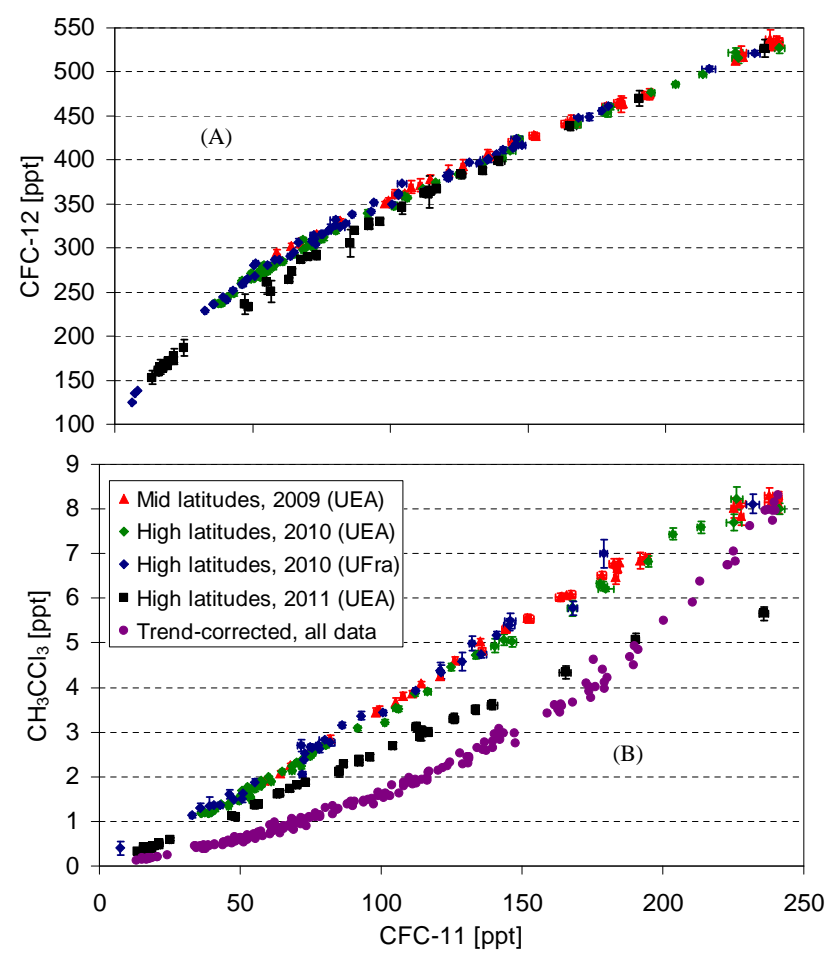

Fig. 2. Compact correlations of CFC-11 mixing ratios with those of CFC-12 (A) and $\mathrm{CH}_{3} \mathrm{CCl}_{3}$ (B) in the mid- and high-latitude stratosphere as obtained from whole-air samples collected during aircraft campaigns in 2009 (red), 2010 (blue and green) and 2011 (black). Analysis of the 2010 samples was split between the University of Frankfurt (UFra, blue) and the University of East Anglia (UEA, green), with excellent agreement between the two data sets for all compounds. When applying a first-order correction for the influence of the changing tropospheric trend, the correlations become very similar (purple). This is only displayed for (B) as the respective changes in tropospheric abundances of CFC-11 and CFC-12 are small and thus the "trend-corrected" correlation is almost indistinguishable from the other correlations.

the tropopause. Our derivation of these slopes and their uncertainties follows again the methods laid out in Volk et al. (1997). A detailed description of the methodology, figures, and the derived slopes are also given in the Supplement. The estimated uncertainties of the derived slopes at the tropopause vary between about $5 \%$ and $33 \%$, depending on the amount of available samples, their precision, and the scatter and the curvature of the correlation with CFC- 11 .

\section{Results and discussion}

\subsection{Fractional release and mean age of air}

Long-lived trace gases form compact intercorrelations in the stratosphere, but these change over time if the respective tropospheric abundances change. This is illustrated in Fig. 2 for the correlations of CFC-12 and $\mathrm{CH}_{3} \mathrm{CCl}_{3}$ with $\mathrm{CFC}-11$ 

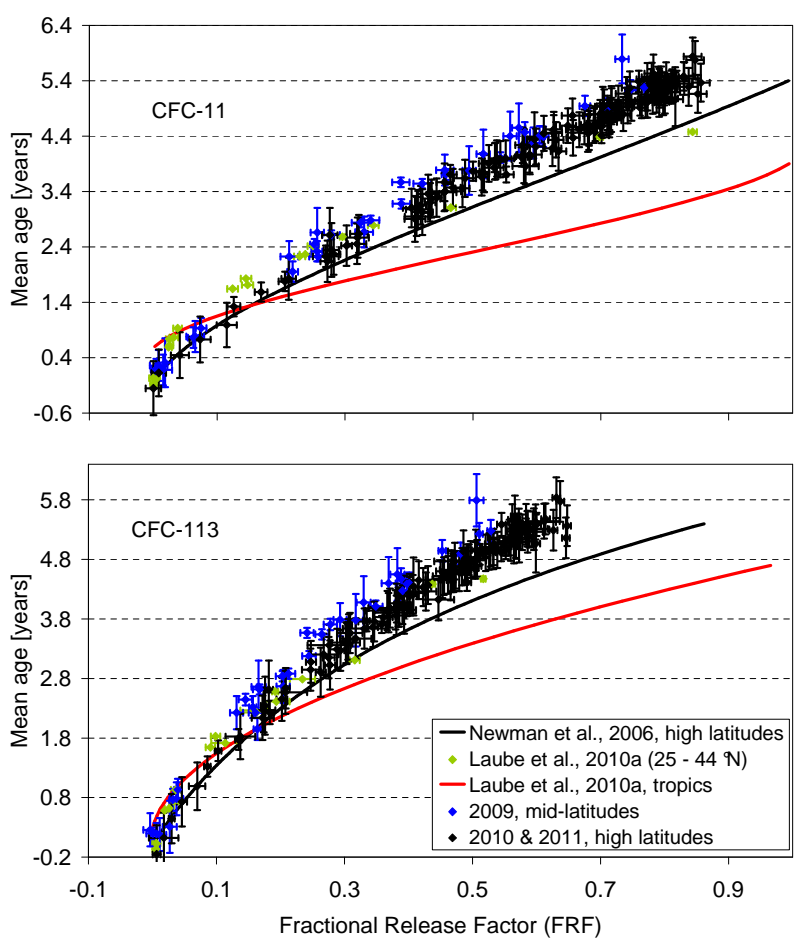

Fig. 3. Correlation of fractional release factors with mean age of air for CFC-11 and CFC-113. High- (black) and mid-latitude (blue) data from this study are shown alongside with tropical and extratropical data from Laube et al. (2010a) (FRFs from 2005 and 2006), as well as high-latitude correlations from Newman et al. (2006) (data from 2000). The error bars were derived using the $1 \sigma$ measurement uncertainty (or its equivalent in mean age). To account for the uncertainty in entrance mixing ratios, we also added the percentage difference between the NOAA-ESRL stations in Tutuila, American Samoa $\left(14.25^{\circ} \mathrm{S}, 170.56^{\circ} \mathrm{W}\right)$, and Mauna Loa, Hawaii, United States $\left(9.54^{\circ} \mathrm{N}, 155.58^{\circ} \mathrm{W}\right)$, as well as the respective NOAA $1 \sigma$ measurement uncertainties, both averaged over 2010. For samples for which mean age was derived from a correlation with CFC-12 (see text), we added an additional error of 0.06 years from the uncertainty of this correlation.

as obtained from the three Geophysica campaigns. Firstly, it is notable from this figure that there is very good agreement between the different laboratories (at UEA and UFra), which has been observed for all compounds reported here. Secondly, in the case of CFC-12 and CFC-11 tropospheric changes have been minor in recent years. Thus the correlations from the three campaigns are very similar. In the case of $\mathrm{CH}_{3} \mathrm{CCl}_{3}$, there is a distinct difference between the first two campaigns which took place in November 2009 and January 2010 and the third campaign almost two years later. Tropospheric abundances of $\mathrm{CH}_{3} \mathrm{CCl}_{3}$ have decreased considerably over this period (WMO, 2011), which is reflected in this correlation. For $\mathrm{CH}_{3} \mathrm{CCl}_{3}$ the discrepancy between the two correlations is also decreasing with increasing decomposition.
Also shown in Fig. 2 is a "trend-corrected" correlation of CFC-11 and $\mathrm{CH}_{3} \mathrm{CCl}_{3}$ which is calculated by multiplying the FRFs with the mixing ratio observed at the tropopause (here: January 2010). Although this first order correction is not expected to yield a correlation representative of a steady state, the differences between the data sets diminish, demonstrating the potential influence of trend changes but also the quality of the applied correction.

Figure 3 shows the FRF correlation with mean age for CFC-11 and CFC-113 in comparison to the polynomial relationships inferred by Newman et al. (2006) from highlatitude flights and Laube et al. (2010a) from tropical and extra-tropical samples. As expected for compounds with photolysis as the major sink, CFC-11 and CFC-113 are decomposing fastest in the tropical stratosphere where the highest actinic fluxes occur. When comparing different latitudes we find similarly to Schauffler et al. (1999) that fractional release is lowest in the mid-latitudinal stratosphere. This can be understood in terms of the seasonal development of the winter/spring polar correlations. Isolation of the polar vortex in association with differential descent and horizontal mixing leads to the formation of separate polar correlations on the concave side of the climatologic mid-latitudinal correlation curves over the course of the winter (Plumb, 2007). For most species considered here, this tends to decrease mixing ratios at a given age surface in the lower stratosphere, and thus increase fractional release. Correlations of the remaining eight compounds are shown in Figs. 4 and 5, with the highest FRFs derived for $\mathrm{H}-1211$ and $\mathrm{CH}_{3} \mathrm{CCl}_{3}$ and the lowest for HCFC-22 and HCFC-142b. Respective polynomial fit functions derived from these correlations can be found in the Supplement.

Also apparent from Figs. 3 to 5 is a discrepancy in comparison to the high-latitude correlations of Newman et al. (2006). Most notably the two dependencies diverge with increasing mean age and FRF. We find this for 7 out of the 10 compounds reported here, i.e. all except HCFC-141b, HCFC-142b and H-1301. Both of the HCFCs still showed significant nonlinear growth rates at the time of sample collection for the work of Newman et al. (2006) (i.e. in 2000) which adds significant uncertainties (as has been noted in Daniel and Velders, 2007). Moreover, for HCFC-142b our data set shows FRFs that are too small to evaluate differences with Newman et al. (2006) within the uncertainties. The Newman et al. (2006) study was also based mostly on data from a high-latitude campaign (Schauffler et al., 2003) but for H-1301 used a completely different data set originating from an earlier campaign and a variety of latitudes (and also with much higher uncertainties; Schauffler et al., 1999). When not considering these three compounds, we find similar divergence between our data set and the correlations of Newman et al. (2006), indicating that the differences might be related to differences in mean age.

Newman et al. (2006) derived mean ages from $\mathrm{CO}_{2}$, whereas we here use $\mathrm{SF}_{6}$. It has been previously shown that 

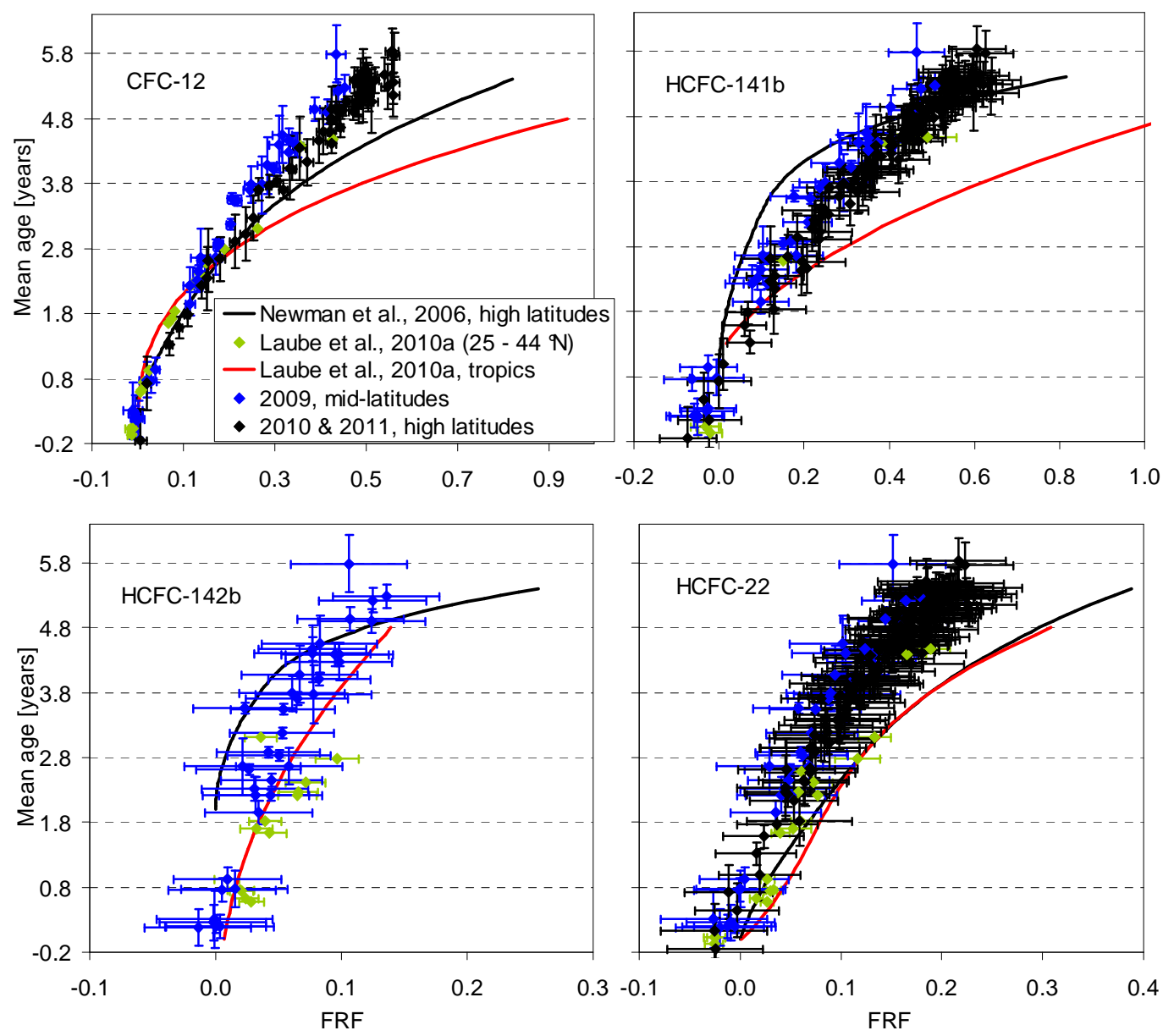

Fig. 4. Same as in Fig. 3 but for CFC-12, HCFC-141b, HCFC-142b and HCFC-22.

both trace gases give comparable mean ages (e.g. Strunk et al., 2000; Engel et al., 2002). An exception can be the middle high-latitudinal stratosphere if influenced by descending mesospheric air depleted in $\mathrm{SF}_{6}$, which results in erroneously high mean ages (e.g. Engel et al., 2006). We have found no evidence for significant mesospheric influence here. Highlatitude data from nine different Geophysica flights all follow the same correlations. Moreover, the high-latitude and the mid-latitude data do not converge as mean age increases. As the mid-latitude data set was obtained in late autumn at altitudes between 10 and $20 \mathrm{~km}$, it is very unlikely to be influenced by mesospheric air. At higher latitudes even small amounts of mesospheric air would result in significantly enhanced mean age as this air contains very little $\mathrm{SF}_{6}$. On the other hand, the FRF of CFC-11 would only be increased slightly as CFC-11 is depleted to very low values in the middle stratosphere already. Therefore the high-latitude FRF-mean-age correlation would approach or even cross the mid-latitude correlation. This is not observed and we conclude that there is no significant mesospheric influence in our data set. An additional confirmation comes from simul- taneous stratospheric measurements of $\mathrm{H}_{2}$ by the HAGAR instrument. Extreme $\mathrm{H}_{2}$ mixing ratios of less than 400 and more than 800 parts per billion (ppb) have been observed in the vicinity of mesospherically influenced air (Engel et al., 2006), but the range observed here was considerably smaller, ranging from 470 to $590 \mathrm{ppb}$.

Mean ages derived from $\mathrm{CO}_{2}$ are not sensitive to mesospheric influences (Engel et al., 2006). If the data set used by Newman et al. (2006) was influenced by mesospheric or even higher stratospheric air, this would lead to a modest shift of the FRF-mean-age correlation similar to the observed difference. Moreover, the arctic stratosphere shows significant interannual variability especially in the winter, which could also explain the observed differences. There are a number of other possible contributors for these differences such as the difficulties in deriving mean ages from $\mathrm{CO}_{2}$, e.g. because of the strong interannual variability of its growth rate (Stiller et al., 2012), and possible long-term changes in stratospheric mean age (Engel et al., 2009 and Stiller et al., 2012).

It has also been noted by Volk et al. (1997) that the effects of stratospheric chemistry and transience (driven by 

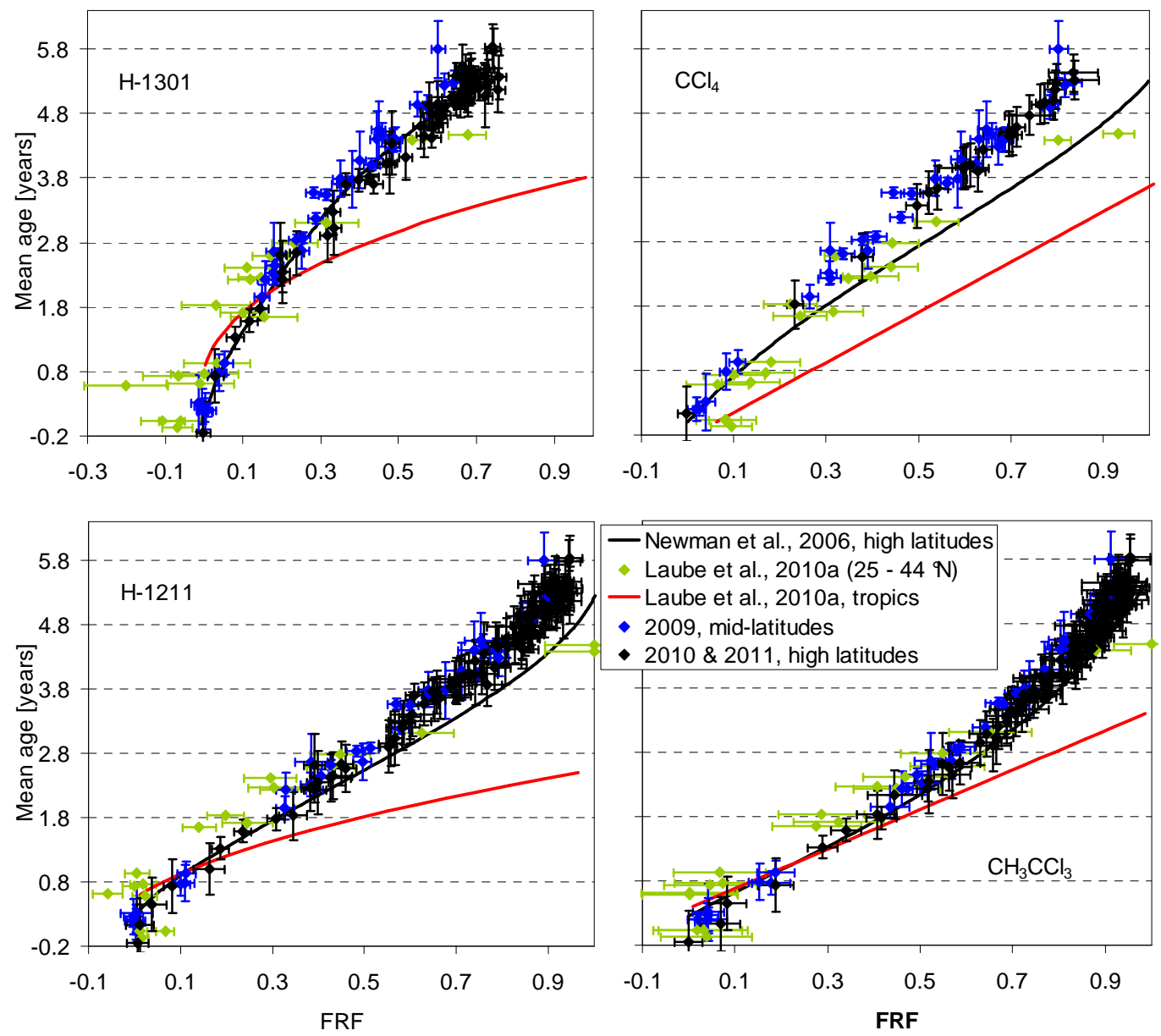

Fig. 5. Same as in Fig. 3 but for $\mathrm{H}-1301, \mathrm{H}-1211, \mathrm{CCl}_{4}$ and $\mathrm{CH}_{3} \mathrm{CCl}_{3}$.

tropospheric growth) are coupled by stratospheric transport and can not be easily separated from each other. To derive steady-state quantities from transient in situ observations, Volk et al. (1997) solved this problem for the simpler case of the gradient at the tropopause, as displayed in Eq. (7) (cf. Eq. (A11) in Volk et al., 1997).

$\frac{d \chi}{d \Gamma}=-\chi_{0}(t) \cdot\left(\beta_{0}+\gamma_{0}-2 \cdot \beta_{0} \cdot \gamma_{0} \cdot \Lambda\right)$

$\frac{d \chi}{d \Gamma}-$ gradient of mixing ratio against mean age at $\Gamma=0$

$\chi_{0}(t)-$ mixing ratio at $\Gamma=0$

Here, $\beta_{0}$ is a term describing the steady state loss rate, while $\gamma_{0}$ is again the effective tropospheric growth rate. Thus a correction for tropospheric growth needs to take into account not only $\gamma_{0}$ but also its interaction with $\beta_{0}$ via the age spectrum $\left(\Lambda=\Delta^{2} / \Gamma\right.$ as noted above) in the last term of Eq. (7). A similar correction of FRFs (or of tracer correlations in general) inside the stratosphere is not possible from observations alone as it would require prior knowledge of stratospheric transport and loss (Volk et al., 1997). Therefore the FRFs derived here can not be considered as equilibrium quantities and are only valid as long as the tropospheric trends of the respective compounds do not significantly change. This could also explain the differences between our FRF-mean-age correlation and that of Newman et al. (2006), especially for HCFC-141b; as growth rates became more linear the shape of this correlation changed significantly. In 2009-2011 it became very similar to that of HCFC-22, which has been growing more linearly since the 1990s (WMO, 2011).

This dependency contradicts a statement in our earlier work (i.e. Laube et al., 2010a) where FRFs were referred to as "time-independent quantities". Nevertheless we find good comparability with the extratropical FRFs from Laube et al. (2010a) (Figs. 3 to 5), indicating no substantial changes between late 2005 and December 2011. It is also possible that the FRFs of eight compounds (i.e. all except HCFC-141b and HCFC-142b) have not even changed significantly since 2000 given that there were no substantial changes in trends. The differences with the correlations of Newman et al. (2006) 
could then instead be related to differences in mean age. The FRFs presented here are more up-to-date than the FRFs used in WMO (2011). However, with the available data it is not possible to resolve their seasonality or the potential variability introduced by the mean age part of these correlations.

\subsection{Stratospheric lifetime evaluation}

Table 2 gives an overview of stratospheric lifetimes reported in the most recent WMO Ozone Assessment (WMO, 2011), Volk et al. (1997), and those derived here including uncertainty ranges. The latter were inferred from uncertainties introduced by the tracer versus CFC- 11 and CFC- 11 versus mean-age correlation slopes, and different widths of the age spectrum. For $\mathrm{CH}_{3} \mathrm{CCl}_{3}$ and $\mathrm{HCFC}-142 \mathrm{~b}$ we also considered the maximum difference between our upper tropospheric and NOAA NH mixing ratios (see Sect. 2). We generally find that the stratospheric lifetime uncertainties are dominated by the two slope uncertainties with a smaller contribution from the different widths of the age spectrum.

Our stratospheric lifetimes were initially calculated assuming a lifetime of 45 years for CFC-11. Based on this assumption our stratospheric lifetimes agree with those in WMO (2011) and Volk et al. (1997) within the uncertainty ranges for six compounds. It should be noted though that for H-1211 only an overall lifetime is given in WMO (2011), and that $\mathrm{H}-1301$ and the three HCFCs were not evaluated in Volk et al. (1997). For three compounds (i.e. CFC-113, CFC-12 and $\mathrm{CH}_{3} \mathrm{CCl}_{3}$ ), we find stratospheric lifetimes that are lower than those in Volk et al. (1997) but still agree within the combined uncertainties - but not with those in WMO (2011). However, there is no uncertainty range given in WMO (2011) so the lifetimes could still agree within the combined respective errors. For $\mathrm{CH}_{3} \mathrm{CCl}_{3}$ we find a $42 \%$ lower stratospheric lifetime than the one presented in WMO (2011). A much smaller stratospheric lifetime of $\mathrm{CH}_{3} \mathrm{CCl}_{3}$ would result in a number of implications. The overall atmospheric $\mathrm{CH}_{3} \mathrm{CCl}_{3}$ lifetime of 5 years (WMO, 2011) is dominated by its $\mathrm{OH}$ loss. Replacing the stratospheric component with our estimate would decrease its overall lifetime by $\approx 0.43$ years or about $8 \%$. Because of its short lifetime with respect to $\mathrm{OH}$, this compound has been used in a number of studies to estimate levels of $\mathrm{OH}$ in the atmosphere (e.g. Krol et al., 2003; Prinn et al., 2005; Montzka et al., 2011). Therefore a significant stratospheric lifetime reduction would have an impact on derived $\mathrm{OH}$ concentrations, which has the potential to change the atmospheric lifetimes of a large number of trace gases that are dominated by reaction with $\mathrm{OH}$.

Table 2 also highlights the limitations of our method to derive lifetimes for compounds that are very long-lived in the stratosphere such as HCFC-22 and HCFC-142b. Because of the small loss rates, the corrected correlation slopes of these compounds are very small, which leads to large uncertainty ranges. In the case of HCFC-142b, we even calculate small negative slopes at the upper end of the lifetime uncertainty range, which is equivalent to an infinite stratospheric lifetime. The only reliable estimate for this compound is therefore the lower end of the lifetime range, which is the minimum stratospheric lifetime. In addition, it is notable that our results only just agree with the lifetimes in WMO (2011) for one further compound. According to our best estimate (and relative to a lifetime of 45 years for CFC-11), $\mathrm{CCl}_{4}$ should be considerably longer-lived than the value given in WMO (2011).

For CFC-12 we note a discrepancy regarding our CFC$12 /$ CFC-11 lifetime ratio (1.66), which is already smaller than that of Volk et al. (1997) (1.92) but differs even more from the one resulting from WMO reports (2.22). It has also been noted in WMO (2011) that "evidence is emerging that lifetimes for some important ODSs (e.g. CFC-11) may be somewhat longer than reported in past assessments". In the case of CFC-11, this is supported by the study of Douglass et al. (2008), which suggested a range of 56 to 64 years for its steady-state lifetime from a number of global models with improved model transport schemes. With respect to CFC-12 Douglass et al. (2008) concluded that the new model results agree better with previous lifetime estimates as compared to CFC-11. For these reasons we derive a second set of lifetimes by assuming a CFC-12 lifetime of 100 years as recommended in WMO (2011) but also because it agrees with the range in Douglass et al. (2008). This here translates into a CFC-11 lifetime of 60.1 years (see Table 2), which falls in the range suggested by Douglass et al. (2008). The resulting stratospheric lifetimes are in this case calculated to be larger than those recommended by WMO (2011) in 5 out of 8 cases. For CFC-11, HCFC-141b, H-1301 and $\mathrm{CCl}_{4}$, even the lower ends of our uncertainty ranges are larger than the WMO lifetimes. These results should be assessed by global models, but it is clear that the sum of such increases would cause a significant delay in projections of the recovery of stratospheric ozone. For $\mathrm{CH}_{3} \mathrm{CCl}_{3}$ our stratospheric lifetime range ( 21 to 43 years) then agrees with the 39 years given in WMO (2011). Using a CFC-11 lifetime of 60.1 years and again directly replacing the stratospheric lifetime in WMO (2011) with our estimate, the resulting change in its overall lifetime would be smaller and equate to a reduction of $\approx 0.19$ years or about $4 \%$.

The last column in Table 2 shows the percentage changes in stratospheric lifetimes that were induced through the trend correction method. It is notable, that these corrections changed lifetime estimates by less than $5 \%$ for five of the compounds reported here: CFC-11, CFC-113, CFC-12, H1211, and $\mathrm{CCl}_{4}$. Due to their small current tropospheric growth rates in recent years (WMO, 2011), these compounds can be considered as close to steady-state. Any unaccounted inaccuracy potentially inherent to our tropospheric trend correction method would thus hardly affect the derived stratospheric lifetime ratios, which gives further confidence in the results for these species. 
Table 2. Comparison of stratospheric lifetimes from WMO (2011), Volk et al. (1997) and this work. The latter two were scaled relative to a CFC-11 lifetime of 45 years. The CFC-11 lifetime of 60.1 years in our work results from assuming a CFC-12 lifetime of 100 years. The uncertainty ranges were derived via Eq. (6) by considering the slope uncertainty in the CFC-11-mean-age correlation as given in the text, slope uncertainties in tracer-CFC-11 correlations (see the Supplement), and values of 0.7 to 1.75 for $\Lambda$. To ensure comparability with the work of Volk et al. (1997), we adopt a $\Lambda$ value of 1.25 for our lifetime calculations.

\begin{tabular}{|c|c|c|c|c|c|c|}
\hline \multirow{3}{*}{ Compound } & \multicolumn{6}{|c|}{ Stratospheric lifetimes } \\
\hline & \multirow{2}{*}{ WMO (2011) } & \multirow{2}{*}{ Volk et al. (1997) } & \multicolumn{4}{|c|}{ This work } \\
\hline & & & $\begin{array}{l}\mathrm{CFC}-11=45 \\
\text { years }\end{array}$ & $\begin{array}{l}\mathrm{CFC}-11=60.1 \\
\text { years }\end{array}$ & Ratio to CFC-11 & $\begin{array}{l}\% \text { change from } \\
\text { trend correction }\end{array}$ \\
\hline CFC-11 & 45 & (45) & (45) & $\begin{array}{l}60 \\
(54-67)\end{array}$ & 1 & 0.7 \\
\hline CFC-113 & 85 & $101 \pm 28$ & $\begin{array}{l}62 \\
(55-69)\end{array}$ & $\begin{array}{l}82 \\
(74-93)\end{array}$ & 1.37 & -4.3 \\
\hline CFC-12 & 100 & $86 \pm 11$ & $\begin{array}{l}75 \\
(67-84)\end{array}$ & $(100)$ & 1.66 & -0.7 \\
\hline HCFC-141b & 64.9 & - & $\begin{array}{l}91 \\
(52-340)\end{array}$ & $\begin{array}{l}122 \\
(70-454)\end{array}$ & 2.02 & 40 \\
\hline HCFC-142b & 160 & - & $\begin{array}{l}304 \\
(104-\infty)\end{array}$ & $\begin{array}{l}406 \\
(139-\infty)\end{array}$ & 6.75 & 80 \\
\hline HCFC-22 & 186 & - & $\begin{array}{l}138 \\
(84-484)\end{array}$ & $\begin{array}{l}184 \\
(113-647)\end{array}$ & 3.06 & 58 \\
\hline H-1301 & 65 & - & $\begin{array}{l}62 \\
(56-69)\end{array}$ & $\begin{array}{l}82 \\
(75-93)\end{array}$ & 1.37 & 15 \\
\hline H-1211 & - & $23 \pm 5$ & $\begin{array}{l}27 \\
(24-31)\end{array}$ & $\begin{array}{l}36 \\
(32-41)\end{array}$ & 0.61 & 0.5 \\
\hline $\mathrm{CCl}_{4}$ & 35 & $32 \pm 4$ & $\begin{array}{l}39 \\
(34-47)\end{array}$ & $\begin{array}{l}53 \\
(45-62)\end{array}$ & 0.87 & -4.4 \\
\hline $\mathrm{CH}_{3} \mathrm{CCl}_{3}$ & 39 & $34 \pm 5$ & $\begin{array}{l}22 \\
(15-32)\end{array}$ & $\begin{array}{l}30 \\
(21-43)\end{array}$ & 0.50 & -155 \\
\hline
\end{tabular}

\subsection{Ozone depletion potentials}

FRFs and stratospheric lifetimes as calculated in the previous sections provide the ingredients for a reassessment of a key quantity: the semi-empirical ozone depletion potential. These can be derived via Eq. (8), which has been adapted from Daniel and Velders (2007).

$\mathrm{QDP}_{i}=\left(\alpha \cdot n_{\mathrm{Br}, i}+n_{C l, i}\right) \cdot \frac{\mathrm{FRF}_{i}}{\mathrm{FRF}_{\mathrm{CFC}-11}} \cdot \frac{\tau_{i}}{\tau_{\mathrm{CFC}-11}} \cdot \frac{M_{\mathrm{CFC}-11}}{M_{i}} \cdot \frac{1}{3}$

where $\alpha$ is relative ozone destruction effectiveness of bromine as compared to chlorine (here 60 as recommended in WMO (2011) for mid-latitudes), $n$ is the number of bromine/chlorine atoms, $\tau$ is the overall atmospheric lifetime, and $M$ is molecular mass.

In the case of CFC-11, CFC-12, CFC-113 and H1301, where no significant tropospheric sinks exist, we use our newly calculated stratospheric lifetimes as equivalent to the overall atmospheric lifetimes. For the remaining six molecules, we use our calculated stratospheric lifetimes along with the non-stratospheric losses reported in WMO (2011) to recalculate overall lifetimes. For H-1211 only the overall lifetime is given in WMO (2011), so we use the tropospheric lifetime of 23 years from Burkholder et al. (1991) combined with our calculated stratospheric lifetime. For comparability to WMO (2011), we calculate new ODPs from our mid-latitudinal FRFs only. The FRFs at a mean age of 3 years and the resulting ODPs are shown in Table 3, both in comparison to values from WMO (2011).
Using the two different lifetimes for CFC-11 (i.e. 45 and 60 years) has a smaller influence on ODPs as compared to FRFs, as the respective lifetime changes of all other compounds are in the same direction, and are thus partly compensated for in Eq. (8). Longer lifetimes have no influence at all in the case of stratospheric lifetimes being equivalent to the overall atmospheric lifetime (i.e. for CFC-12, CFC-113, and $\mathrm{H}-1301)$ as the lifetime ratio then remains unchanged. In the case of significant extra-stratospheric sinks, the ODPs are generally found to decrease with increasing stratospheric lifetime. This is caused by the fact that a downscaled change in overall lifetime is then related to a bigger change in CFC11 lifetime in Eq. (8). In the case of the HCFCs, the actual stratospheric lifetimes are accompanied by a large uncertainty range. However, this has very little influence on the ODP as the overall lifetimes of these compounds are dominated by their lifetime with respect to $\mathrm{OH}$.

In comparison to WMO (2011), we find lower ODPs for most compounds. To place this into context, our values would lead to a $22 \%$ reduction in the equivalent chlorine released by these compounds at a mean age of 3 years (i.e. from 1121 to $871 \mathrm{ppt}$ in January 2010). The reductions are most pronounced for the three HCFCs, where, depending on the CFC-11 lifetime, we calculate ODPs that are 30 to $60 \%$ (CFC-11 lifetime of 45 years) or 46 to $70 \%$ (CFC-11 lifetime of 60 years) smaller than those in WMO (2011). Reductions of 13 and $26 \%$ are found for the ODP of $\mathrm{H}-1211$, whereas for $\mathrm{H}-1301$ we derive an $18 \%$ higher ODP. The latter change in 
Table 3. Overview of FRFs derived from mid-latitude polynomial fit functions (see Supplement) at a mean age of 3 years. Uncertainties are calculated by fitting polynomials through the upper and lower envelopes exhibited by the FRF and mean-age error bars displayed in Figs. 3 to 5. Also shown are semi-empirical ozone depletion potentials calculated using these FRFs and the stratospheric lifetimes from Table 2 in comparison to recent estimates from WMO (2011). The ODP ranges additionally consider the stratospheric lifetime ranges from Table 2.

\begin{tabular}{|c|c|c|c|c|c|}
\hline \multirow{2}{*}{ Compound } & \multicolumn{2}{|c|}{ FRF at $\Gamma=3$ years } & \multicolumn{3}{|c|}{ Semi-empirical ODPs } \\
\hline & WMO (2011) & This work & WMO (2011) & $\begin{array}{l}\text { This work, CFC } \\
45 \mathrm{y}\end{array}$ & $\begin{array}{l}1= \\
60.1 \mathrm{y}\end{array}$ \\
\hline CFC-11 & 0.47 & $\begin{array}{l}0.35 \\
(0.32-0.39)\end{array}$ & 1 & 1 & 1 \\
\hline CFC-113 & 0.29 & $\begin{array}{l}0.22 \\
(0.20-0.25)\end{array}$ & 0.85 & $\begin{array}{l}0.63 \\
(0.57-0.69)\end{array}$ & $\begin{array}{l}0.63 \\
(0.57-0.69)\end{array}$ \\
\hline CFC-12 & 0.23 & $\begin{array}{l}0.19 \\
(0.16-0.21)\end{array}$ & 0.82 & $\begin{array}{l}0.67 \\
(0.59-0.75)\end{array}$ & $\begin{array}{l}0.67 \\
(0.59-0.75)\end{array}$ \\
\hline HCFC-141b & 0.34 & $\begin{array}{l}0.17 \\
(0.14-0.21)\end{array}$ & 0.12 & $\begin{array}{l}0.082 \\
(0.066-0.099)\end{array}$ & $\begin{array}{l}0.063 \\
(0.051-0.076)\end{array}$ \\
\hline HCFC-142b & 0.17 & $\begin{array}{l}0.05 \\
(0.04-0.06)\end{array}$ & 0.06 & $\begin{array}{l}0.025 \\
(0.020-0.032)\end{array}$ & $\begin{array}{l}0.019 \\
(0.015-0.025)\end{array}$ \\
\hline HCFC-22 & 0.13 & $\begin{array}{l}0.07 \\
(0.05-0.08)\end{array}$ & 0.04 & $\begin{array}{l}0.025 \\
(0.019-0.032)\end{array}$ & $\begin{array}{l}0.019 \\
(0.015-0.025)\end{array}$ \\
\hline H-1301 & 0.28 & $\begin{array}{l}0.26 \\
(0.24-0.29)\end{array}$ & 15.9 & $\begin{array}{l}18.7 \\
(17.0-20.3)\end{array}$ & $\begin{array}{l}18.7 \\
(17.0-20.3)\end{array}$ \\
\hline H-1211 & 0.62 & $\begin{array}{l}0.52 \\
(0.48-0.56)\end{array}$ & 7.9 & $\begin{array}{l}6.9 \\
(6.2-7.7)\end{array}$ & $\begin{array}{l}5.8 \\
(5.2-6.5)\end{array}$ \\
\hline $\mathrm{CCl}_{4}$ & 0.56 & $\begin{array}{l}0.42 \\
(0.39-0.46)\end{array}$ & 0.82 & $\begin{array}{l}0.90 \\
(0.84-0.96)\end{array}$ & $\begin{array}{l}0.82 \\
(0.77-0.87)\end{array}$ \\
\hline $\mathrm{CH}_{3} \mathrm{CCl}_{3}$ & 0.67 & $\begin{array}{l}0.61 \\
(0.56-0.65)\end{array}$ & 0.16 & $\begin{array}{l}0.18 \\
(0.17-0.20)\end{array}$ & $\begin{array}{l}0.14 \\
(0.13-0.16)\end{array}$ \\
\hline
\end{tabular}

ODP is mostly induced by the lower FRF of CFC-11 as our H-1301 FRF does not differ much from that in WMO (2011). It should also be noted that differences to WMO values are intensified through the exclusive use of mid-latitude data in our study. As already stated in Sect. 4.1, we find less fractional release in mid-latitudes as compared to high latitudes. Although a mean age of 3 years is supposed to represent midlatitudes, the values in WMO (2011) are mostly based on correlations from Newman et al. $(2006,2007)$ which originate from both mid- and high-latitude data $\left(52\right.$ to $88^{\circ} \mathrm{N}$, Schauffler et al., 2003). Our results suggest that it may be recommendable to distinguish between these two stratospheric regions.

\section{Conclusions}

We have reassessed three policy-relevant parameters for 10 important ozone-depleting substances: fractional release, steady-state lifetimes, and semi-empirical ODPs. For the derived correlations of FRFs with mean age, we find differences to the work of Newman et al. (2006) which could be related to differences in mean age. Especially in the case of HCFC-141b and HCFC-142b, the differences might additionally be related to temporal changes in relative tropospheric growth rates. Experimentally derived correlations of
FRFs with mean age of air should thus only be considered as time-independent as long as there are no major changes in stratospheric transport or relative tropospheric growth rates. When using such correlations the uncertainties connected to the mean age of air and its calculation could be very substantial. We can, for instance, not assess seasonal or hemispheric variability with the available data set. However, we do find differences between mid- and high-latitude fractional release, and this should be taken into account when assessing ozone recovery scenarios for different latitudinal regions. It is also recommended to further investigate the variability of the FRF-mean-age correlations as they have the potential to significantly alter the projected time of stratospheric ozone recovery.

The stratospheric lifetimes derived here depend on a reliable estimate of the lifetime of CFC-11, as they are calculated relative to it. When adopting a lifetime of 45 years as recommended by WMO (2011), we find agreement with other WMO lifetimes within our uncertainties for 5 of the 8 compounds reported in both works. However, our best estimates suggest a $42 \%$ reduced stratospheric lifetime of $\mathrm{CH}_{3} \mathrm{CCl}_{3}$. Using a CFC-12 lifetime of 100 years yields a CFC-11 lifetime of 60 years, which agrees with the range that has recently been inferred by models (Douglass et al., 2008). A longer CFC-11 lifetime then reduces the $\mathrm{CH}_{3} \mathrm{CCl}_{3}$ 
stratospheric lifetime difference to $23 \%$ but also gives $34 \%$ larger lifetimes for all compounds. This would result in WMO stratospheric lifetime recommendations being below our estimated ranges for CFC-11, HCFC-141b, H-1301 and $\mathrm{CCl}_{4}$. However, we are unable to resolve the discrepancy between WMO (2011) and Douglass et al. (2008) here. In the absence of an updated and independent estimate of the lifetime of CFC-11, we recommend the internally consistent stratospheric lifetime ratios given in Table 2. It is notable though that our CFC-12/CFC-11 lifetime ratio is closer to that inferred by Volk et al. (1997) and Douglass et al. (2008), whereas the ratio given in WMO (2011) is considerably higher.

The ozone depletion potentials derived from the FRFs and lifetimes above are in most cases smaller than those recommended by WMO (2011). We also note that according to our results HCFCs are considerably less harmful to stratospheric ozone than assumed in past WMO assessments, with reductions in their ODPs of up to $70 \%$. A corollary of these smaller ODPs, however, is that stratospheric ozone recovery might be more delayed than previously determined, as a result of the reduced FRFs and possibly longer atmospheric lifetimes of these ODSs. Finally, semi-empirical ODPs should not be considered as time-independent if they are based on observationally derived fractional release factors, for the above mentioned reasons.

\section{Supplementary material related to this article is

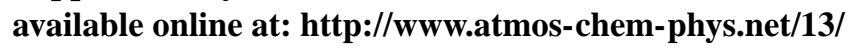 2779/2013/acp-13-2779-2013-supplement.zip.}

\section{References}

Bönisch, H., Engel, A., Curtius, J., Birner, T., and Hoor, P.: Quantifying transport into the lowermost stratosphere using simultaneous in-situ measurements of $\mathrm{SF}_{6}$ and $\mathrm{CO}_{2}$, Atmos. Chem. Phys., 9, 5905-5919, doi:10.5194/acp-9-5905-2009, 2009.

Burkholder, J. B., Wilson, R. R., Gierczak, T., Talukdar, R., McKeen, S. A., Orlando, J. J., Vaghjiani, G. L., and Ravishankara, A. R.: Atmospheric fate of $\mathrm{CF}_{3} \mathrm{Br} \mathrm{CF}_{2} \mathrm{Br}_{2}, \mathrm{CF}_{2} \mathrm{ClBr}$, and $\mathrm{CF}_{2} \mathrm{BrCF}_{2} \mathrm{Br}$, J. Geophys. Res., 96, 5025-5043, 1991.

Cairo, F., Pommereau, J. P., Law, K. S., Schlager, H., Garnier, A., Fierli, F., Ern, M., Streibel, M., Arabas, S., Borrmann, S., Berthelier, J. J., Blom, C., Christensen, T., D’Amato, F., Di Donfrancesco, G., Deshler, T., Diedhiou, A., Durry, G., Engelsen, O., Goutail, F., Harris, N. R. P., Kerstel, E. R. T., Khaykin, S., Konopka, P., Kylling, A., Larsen, N., Lebel, T., Liu, X., MacKenzie, A. R., Nielsen, J., Oulanowski, A., Parker, D. J., Pelon, J., Polcher, J., Pyle, J. A., Ravegnani, F., Riviere, E. D., Robinson, A. D., Rockmann, T., Schiller, C., Simoes, F., Stefanutti, L., Stroh, F., Some, L., Siegmund, P., Sitnikov, N., Vernier, J. P., Volk, C. M., Voigt, C., von Hobe, M., Viciani, S., and Yushkov, V.: An introduction to the SCOUT-AMMA stratospheric aircraft, balloons and sondes campaign in West Africa, August 2006: rationale and roadmap, rationale and roadmap, Atmos. Chem. Phys., 10, 2237-2256, doi:10.5194/acp-10-2237-2010, 2010.

Cantrell, C. A.: Technical Note: Review of methods for linear leastsquares fitting of data and application to atmospheric chemistry problems, Atmos. Chem. Phys., 8, 5477-5487, doi:10.5194/acp8-5477-2008, 2008.

Daniel, J. S., Solomon, S. and Albritton, D. L.: On the evaluation of halocarbon radiative forcing and global warming potentials, J. Geophys. Res., 100, 1271-1285, 1995.

Daniel, J. S., Velders, G. J. M., Douglass, A. R., Forster, P. M. D., Hauglustaine, D. A., Isaksen, I. S. A., Kuijpers, L. J. M., McCulloch, A., and Wallington, T. J.: Halocarbon scenarios, ozone depletion potentials, and global warming potentials, Chapter 8 in World Meteorological Organization: Scientific assessment of ozone depletion: 2006, Global Ozone Research and Monitoring Project - Report No. 50, Geneva, 2007.

Douglass, A. R., Stolarski, R. S., Schoeberl, M. R., Jackman, C. H., Gupta, M. L., Newman, P. A., Nielsen, J. E., and Fleming, E. L.: Relationship of loss, mean age of air and the distribution of CFCs to stratospheric circulation and implications for atmospheric lifetimes, J. Geophys. Res., 113, D14309, doi:10.1029/2007JD009575, 2008.

Engel, A., Strunk, M., Müller, M., Haase, H.-P., Poss, C., Levin, I., and Schmidt, U.: Temporal development of total chlorine in the high-latitude stratosphere based on reference distributions of mean age derived from $\mathrm{CO}_{2}$ and $\mathrm{SF}_{6}$, J. Geophys. Res., 107, 4136, doi:10.1029/2001JD000584, 2002.

Engel, A., Möbius, T., Haase, H.-P., Bönisch, H., Wetter, T., Schmidt, U., Levin, I., Reddmann, T., Oelhaf, H., Wetzel, G., Grunow, K., Huret, N., and Pirre, M.: Observation of mesospheric air inside the arctic stratospheric polar vortex in early 2003, Atmos. Chem. Phys., 6, 267-282, doi:10.5194/acp-6-2672006, 2006.

Engel, A., Mobius, T., Bönisch, H., Schmidt, U., Heinz, R., Levin, I., Atlas, E., Aoki, S., Nakazawa, T., Sugawara, S., Moore, F., Hurst, D., Elkins, J., Schauffler, S., Andrews, A., and Boering, K.: Age of stratospheric air unchanged within uncertainties over 
the past 30 years, Nat. Geosci., 2, 28-31, doi:10.1038/Ngeo388, 2009.

Hall, B.D., Dutton, G. S., Mondeel, D. J. Nance, J. D., Rigby, M., Butler, J. H., Moore, F. L., Hurst, D. F., and Elkins, J. W.: Improving measurements of $\mathrm{SF}_{6}$ for the study of atmospheric transport and emissions, Atmos. Meas. Tech., 4, 2441-2451, doi:10.5194/amt-4-2441-2011, 2011.

Harnisch, J., Borchers, R., Fabian, P., and Maiss, M.: Tropospheric trends for CF4 and C2F6 since 1982 derived from SF6 dated stratospheric air, Geophys. Res. Lett., 23, 1099-1102, 1996.

Kaiser, J., Engel, A., Borchers, R., and Röckmann, T.: Probing stratospheric transport and chemistry with new balloon and aircraft observations of the meridional and vertical $\mathrm{N}_{2} \mathrm{O}$ isotope distribution, Atmos. Chem. Phys., 6, 3535-3556, doi:10.5194/acp6-3535-2006, 2006.

Krol, M. C., Lelieveld, J. , Oram, D.E., Sturrock, G.A., Penkett, Brenninkmeijer, C. A.M., Gros, V., Williams, J., and Scheeren, H. A.: Continuing emissions of methyl chloroform from Europe, Nature, 421, 131-135, 2003.

Laube, J. C., Engel, A., Bönisch, H., Möbius, T., Worton, D. R., Sturges, W. T., Grunow, K., and Schmidt, U.: Contribution of very short-lived organic substances to stratospheric chlorine and bromine in the tropics - a case study, Atmos. Chem. Phys., 8, 7325-7334, doi:10.5194/acp-8-7325-2008, 2008.

Laube, J. C., Engel, A., Bönisch, H., Möbius, T., Sturges, W. T., Braß, M., and Röckmann, T.: Fractional release factors of long-lived halogenated organic compounds in the tropical stratosphere, Atmos. Chem. Phys., 10, 1093-1103, doi:10.5194/acp10-1093-2010, 2010a.

Laube, J. C., Martinerie, P., Witrant, E., Blunier, T., Schwander, J., Brenninkmeijer, C. A. M., Schuck, T. J., Bolder, M., Röckmann, T., van der Veen, C., Bönisch, H., Engel, A., Mills, G. P., Newland, M. J., Oram, D. E., Reeves, C. E., and Sturges, W. T.: Accelerating growth of HFC-227ea (1,1,1,2,3,3,3-heptafluoropropane) in the atmosphere, Atmos. Chem. Phys., 10, 5903-5910, doi:10.5194/acp-10-5903-2010, 2010b.

Levin, I. and Hesshaimer, V.: Refining of atmospheric transport model entries by the globally observed passive tracer distributions of ${ }^{85}$ Krypton and sulphur hexafluoride $\left(\mathrm{SF}_{6}\right)$, J. Geophys. Res., 101, 16745-16755, 1996.

Montzka, S. A., Butler, J. H., Elkins, J. W., Thompson, T. M., Clarke, A. D., and Lock, L. T.: Present and future trends in the atmospheric burden of ozone-depleting halogens, Nature, 398, 690-694, doi:10.1038/19499, 1999.

Montzka, S. A., Krol, M., Dlugokencky, E., Hall, B., Jockel, P., and Lelieveld, J.: Small interannual variability of global atmospheric hydroxyl, Science, 331, 67-69, 2011.

Newland, M. J., Reeves, C. E., Oram, D. E., Laube, J. C., Sturges, W. T., Hogan, C., Begley, P., and Fraser, P. J.: Southern hemispheric halon trends and global halon emissions, 1978-2011, Atmos. Chem. Phys. Discuss., 12, 29289-29324, doi:10.5194/acpd-12-29289-2012, 2012.

Newman, P. A., Nash, E. R., Kawa, S. R., Montzka, S. A., and Schauffler, S. M.: When will the Antarctic ozone hole recover?, Geophys. Res. Lett., 33, L12814, doi:10.1029/2005GL025232, 2006.
Newman, P. A., Daniel, J. S., Waugh, D. W., and Nash, E. R.: A new formulation of equivalent effective stratospheric chlorine (EESC), Atmos. Chem. Phys., 7, 4537-4552, doi:10.5194/acp7-4537-2007, 2007.

Plumb, R. A.: A “tropical pipe" model of stratospheric transport, J. Geophys. Res., 101, 3957-3972, 1996.

Plumb, R. A.: Tracer interrelationships in the stratosphere, Rev. Geophys., 45, RG4005, doi:10.1029/2005rg000179, 2007.

Plumb, R. A. and Ko, M. K. W.: Interrelationships between mixing ratios of long-lived stratospheric constituents, J. Geophys. Res. 97, 10145-10156, 1992.

Prinn, R. G., Huang, J., Weiss, R. F., Cunnold, D. M., Fraser, P. J., Simmonds, P. G., McCulloch, A., Harth, C., Reimann, S., Salameh, P., O’Doherty, S., Wang, R. H. J., Porter, L. W., Miller, B. R., and Krummel, P. B.: Evidence for variability of atmospheric hydroxyl radicals over the past quarter century, Geophys. Res. Lett., 32, L07809, doi:10.1029/2004GL022228, 2005.

Schauffler, S. M., Atlas, E. L., Blake, D. R., Flocke, F., Lueb, R. A., Lee-Taylor, J. M., Stroud, V., and Travnicek, W.: Distributions of brominated organic compounds in the troposphere and lower stratosphere, J. Geophys. Res., 104, 21513-21535, 1999.

Schauffler, S. M., Atlas, E. L., Donnelly, S. G., Andrews, A., Montzka, S. A., Elkins, J. W., Hurst, D. F., Romashkin, P. A., Dutton, G. S., and Stroud, V.: Chlorine budget and partitioning during SOLVE, J. Geophys. Res., 108, 4173, doi:10.1029/2001JD002040, 2003.

Solomon, S., Tuck, A. F., Mills, M., Heidt, L. E., and Pollock, W. H.: On the evaluation of ozone depletion potentials, J. Geophys. Res., 97, 825-842, 1992.

Solomon, S. and Albritton, D. L.: Time-dependent ozone depletion potentials for short- and long-term forecasts, Nature 357, 33-37, doi:10.1038/357033a0, 1992.

Stiller, G. P., von Clarmann, T., Haenel, F., Funke, B., Glatthor, N., Grabowski, U., Kellmann, S., Kiefer, M., Linden, A., Lossow, S., and López-Puertas, M.: Observed temporal evolution of global mean age of stratospheric air for the 2002 to 2010 period, Atmos. Chem. Phys., 12, 3311-3331, 2012, doi:10.5194/acp-12-33112012, 2012.

Strunk, M., Engel, A. Schmidt, U. Wetter, T. Levin, I., and GlatzelMattheier, $\mathrm{H} .: \mathrm{CO}_{2}$ and $\mathrm{SF}_{6}$ as stratospheric age tracers: Consistency and the effect of mesospheric SF6-loss, Geophys. Res. Lett., 27, 341-344, 2000.

Volk, C. M., Elkins, J. W., Fahey, D. W., Sutton, G. S., Gilligan, J. M., Loewenstein, M., Podolske, J. R., Chan, K. R., and Gunson, M. R.: Evaluation of source gas lifetimes from stratospheric observations, J. Geophys. Res., 102, 25543-25564, 1997.

Werner, A., Volk, C. M., Ivanova, E. V., Wetter, T., Schiller, C., Schlager, H. and Konopka, P.: Quantifying transport into the Arctic lowermost stratosphere, Atmos. Chem. Phys., 10, 11623 11639, doi:10.5194/acp-10-11623-2010, 2010.

WMO: Scientific Assessment of Stratospheric Ozone: 1989, Global Ozone Research and Monitoring Project - Report No. 20, World Meteorological Organization, Geneva, Switzerland, 1990.

WMO: Scientific Assessment of Ozone Depletion: 2010, Global Ozone Research and Monitoring Project, Report No. 52, World Meteorological Organization, Geneva, Switzerland, 2011. 